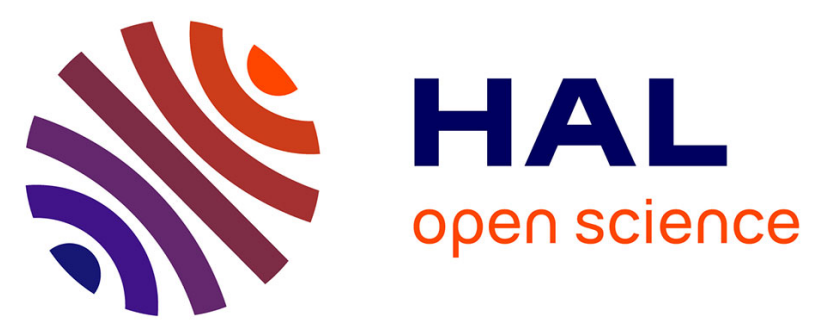

\title{
DIGISOIL: An Integrated System of Data Collection Technologies for Mapping Soil Properties
}

Gilles Grandjean, Olivier Cerdan, Guy Richard, Isabelle Cousin, Philippe Lagacherie, Alain Tabbagh, Bas van Wesemael, Antoine Stevens, Sébastien Lambot, Florence Carre, et al.

\section{To cite this version:}

Gilles Grandjean, Olivier Cerdan, Guy Richard, Isabelle Cousin, Philippe Lagacherie, et al.. DIGISOIL: An Integrated System of Data Collection Technologies for Mapping Soil Properties. Proximal Soil Sensing, Springer, pp.89-101, 2010, Progress in soil science, 978-90-481-8858-1 978-90-4818859-8 978-94-007-3288-9. 10.1007/978-90-481-8859-8_7 . hal-00548807

\section{HAL Id: hal-00548807 https: / hal-brgm.archives-ouvertes.fr/hal-00548807}

Submitted on 20 Dec 2010

HAL is a multi-disciplinary open access archive for the deposit and dissemination of scientific research documents, whether they are published or not. The documents may come from teaching and research institutions in France or abroad, or from public or private research centers.
L'archive ouverte pluridisciplinaire HAL, est destinée au dépôt et à la diffusion de documents scientifiques de niveau recherche, publiés ou non, émanant des établissements d'enseignement et de recherche français ou étrangers, des laboratoires publics ou privés. 


\title{
Chapter 7 \\ DIGISOIL: An Integrated System of Data Collection Technologies for Mapping Soil Properties
}

\author{
G. Grandjean, O. Cerdan, G. Richard, I. Cousin, P. Lagacherie, A. Tabbagh, \\ B. Van Wesemael, A. Stevens, S. Lambot, F. Carré, R. Maftei, T. Hermann, \\ M. Thörnelöf, L. Chiarantini, S. Moretti, A. McBratney, and E. Ben Dor
}

\begin{abstract}
The multidisciplinary DIGISOIL consortium intends to integrate and improve in situ proximal measurement technologies for assessing soil properties and soil degradation indicators, moving from the sensing technologies themselves to their integration and application in (digital) soil mapping (DSM). The core objective of the project is to explore and exploit new capabilities of advanced geophysical technologies for answering this societal demand. To this aim, DIGISOIL addresses four issues covering technological, soil science, and economic aspects: (i) development and validation of hydrogeophysical technologies and integrated pedogeophysical inversion techniques; (ii) the relation between geophysical parameters and soil properties; (iii) the integration of derived soil properties for mapping soil functions and soil threats; and (iv) the evaluation, standardisation, and industrialisation of the proposed methodologies, including technical and economic studies.
\end{abstract}

Keywords Soil properties · Sensing technologies · Geophysical techniques · Inference model · Water content

\subsection{Introduction}

The main objective of the European FP7 Cooperation Work Program on Environment ${ }^{1}$ proposes to address global environmental issues in an integrated way by advancing our knowledge and capacities to develop new technologies for sustainable management of the environment and its resources. The DIGISOIL

\footnotetext{
G. Grandjean (凶)

BRGM, Orléans, France

e-mail: g.grandjean@brgm.fr

${ }^{1}$ Framework Program 7.
} 
project started in autumn 2008. As with the iSoil project (Chapter 8), it is defined according to the FP7 work program and addresses 'technologies for data collection in (digital) soil mapping'. The multidisciplinary DIGISOIL consortium aims to integrate and improve in situ and proximal measurement technologies for the assessing soil properties and soil degradation indicators, moving from the sensing technologies themselves to their integration and application in (digital) soil mapping (DSM).

In order to assess and prevent soil degradation and to benefit from the different ecological, economic, and historical functions of the soil in a sustainable way, there is an obvious need for high-resolution, accurate maps of soil properties. The core objective of the project is to explore and exploit new capabilities of advanced geophysical technologies for answering this societal demand. To this end, DIGISOIL addresses four issues covering technological, soil science, and economic aspects (Fig. 7.1): (i) the validation of geophysical (in situ, proximal, and airborne) technologies and integrated hydrogeophysical inversion techniques (mechanistic data fusion); (ii) the relation between geophysical parameters and soil properties; (iii) the integration of derived soil properties for mapping soil functions and soil threats; and (iv) the evaluation, standardisation, and industrialisation of the proposed methodologies, including technical and economic studies.

\subsection{Objectives}

The purpose of the DIGISOIL project is to identify and bridge the technological gap and develop pertinent, reliable, and cost-effective geophysical mapping solutions. Considering the new equipment and signal processing developments offered by recent scientific investigations, the problem of performing soil data collections at the catchment scale using geophysical sensors can be foreseen in the near future, particularly for methods identified in the following tables (GPR, EMI, seismics, magnetics, and airborne hyperspectral) (Tables 7.1 and 7.2).Gravity-based and thermal-based methods will not be incorporated in DIGISOIL because of their low contribution to the characterisation of soil properties related to degradation processes. For gamma radiometrics, several investigations have already been carried out to study their potential for soil properties mapping (e.g. Viscarra Rossel et al., 2007). This technology has given satisfactory results and permits one to map types of clay minerals in the topsoil through the analysis of $\mathrm{U}, \mathrm{K}$, and Th anomalies in the gamma spectrum. We will not consider this method since it appears to be already used in the soil science community (Wilford and Minty, 2006). However, since the information provided by this technology has many interesting aspects, we will integrate it as potential auxiliary data in our mapping strategy. This context is therefore favourable for the development of DIGISOIL's mapping tools and products in relation to DSM applications. With respect to these issues, the milestones of the DIGISOIL project are 
7 DIGISOIL: An Integrated System of Data Collection Technologies

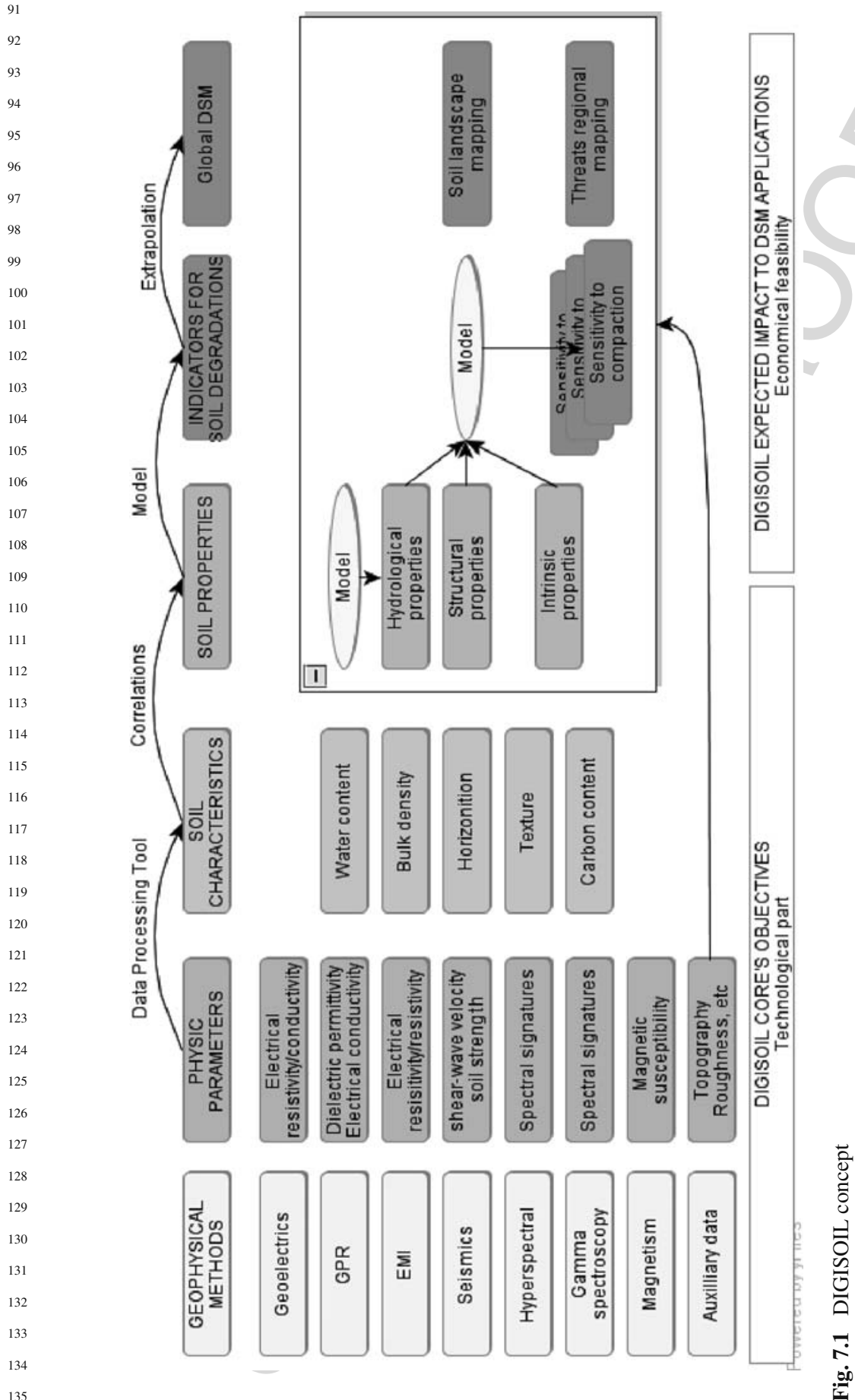


Table 7.1 Common elements for the identification of risk areas

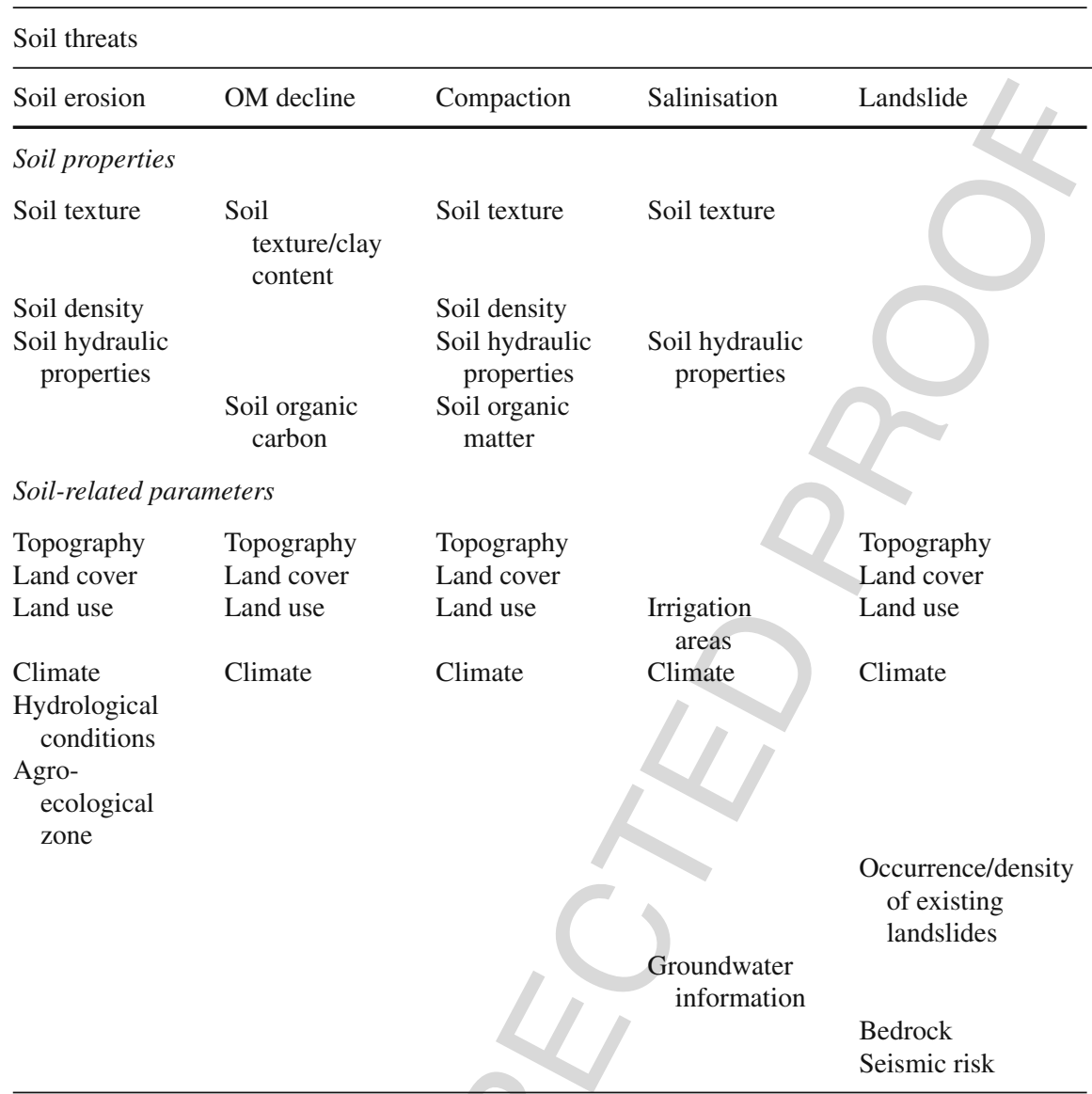

1. To develop, test, and validate the most relevant geophysical technologies for mapping soil properties: geoelectric, seismic, GPR/EMI, magnetic, and airborne hyperspectral.

2. To establish correlations between the measured geophysical measurements and the soil properties involved in soil functions/threats (erosion, compaction, organic matter decline, salinisation, and shallow landslides) by using innovative data processing (inversion) and correlation protocols.

3. To evaluate the societal impact of the developed techniques by investigating their relevance to end-user needs, their technical feasibility, and their cost-effectiveness.

4. To produce an exploitation plan including the standardisation of the processes and the technical specifications of the developed methodologies describing the system components in terms of equipment (sensors, acquisition system, 
DIGISOIL: An Integrated System of Data Collection Technologies

\subsection{Strategy and Workplan}

The DIGISOIL architecture is structured according to five items in relation to the above-cited objectives of the project:

1. Identification of pertinent sensor technologies: the capabilities of the different geophysical techniques will be investigated and technically adapted so as to characterise highly complex soil properties (spatial and temporal heterogeneities, low variations of properties, context-dependant, etc.). Two series of experiments will be carried out with a two-step feedback approach in order to analyse sequentially, and on different sites, the quality of the results and the efficiency of each technology.

2. The data integration for estimating soil properties: the conversion of geophysical parameters into soil properties and the derivation of soil threats are not straightforward. Most of the time, several indicators are necessary to reduce the uncertainty of the estimation. Studying the different correlation between indicators and possible soil properties should finally lead to an innovative methodology of fusion, guaranteeing a final assessment in terms of soil diagnostics (soil properties, threats, and soil functions).

3. Testing and validation on selected sites: the Commission policies have to deal with various European environments. For that reason, the sensor technologies will be tested on two series of sites: (i) second-order test sites for a specific 
technique adaptation and (ii) first-order sites for testing the validity domain of different sensors at the same location. The latter have been selected in order to ensure a maximal geographical representativeness within Europe. For this validation task, classical in situ invasive sensors will be used.

4. Evaluation of the proposed methodologies: as the intent is oriented towards serving DSM applications, the results should be evaluated in terms of technical feasibility, maturity, and economical costs.

5. Exploitation of the proposed methodology: with respect to the Work Program's objectives, which stipulate that technologies developed in the Collaboration Program have to be finally exploited as European services, an exploitation plan, including technical specifications of the developed methodologies, will be presented.

\subsection{From Soil Threats to Geophysical Properties}

The DIGISOIL project can be seen as the setting up of operational techniques useful for implementing existing and emerging EU environmental legislation and policy like the European Soil Thematic Strategy, which aims to protect soil functions and prevent soil degradation. Table 7.3 represents the main soil and soil-related parameters to be considered by member states for delineating risk areas. Since soil texture, soil water content, soil hydraulic properties, bulk density, and soil organic matter are involved in many soil functions, these properties have to be considered the first priority. Soils under threat cannot continue to perform all their environmental, economic, social, and cultural functions in the same way after being degraded (e.g. biomass production is not possible on sealed soils). The gradual loss of performance of soil functions depends on the severity of a threat, which can be gauged in terms

Table 7.3 Main ground-based and airborne geophysical methods and related physical parameters. Italics indicate methods that will not be integrated into the DIGISOIL tool

\begin{tabular}{|c|c|}
\hline Geophysical methods & Physical parameters \\
\hline Ground-penetrating radar (GPR) & $\begin{array}{l}\text { Dielectric permittivity, electric conductivity, } \\
\text { magnetic permeability, frequency dependence of } \\
\text { these electromagnetic properties }\end{array}$ \\
\hline Seismic reflection and refraction & Volume and shear-wave velocities \\
\hline Electromagnetic induction (EMI) & $\begin{array}{l}\text { Electrical resistivity (electric conductivity and } \\
\text { frequency dependence) }\end{array}$ \\
\hline Electrical resistivity (geoelectric) & Electrical resistivity (almost zero-frequency) \\
\hline Gravity & Density \\
\hline Magnetics & Magnetic susceptibility and viscosity \\
\hline Airborne thermic & Surface temperature \\
\hline Airborne hyperspectral & Spectral reflectance \\
\hline Gammametry & Gamma spectrum $(U, K, T h)$ \\
\hline
\end{tabular}


DIGISOIL: An Integrated System of Data Collection Technologies

Table 7.4 PLS regression output statistics of the best model for each dataset

\begin{tabular}{|c|c|c|c|c|c|c|c|}
\hline \multirow[b]{2}{*}{ Data } & \multicolumn{3}{|c|}{ Calibration } & \multicolumn{4}{|c|}{ Validation } \\
\hline & $\mathrm{N}$ & $\begin{array}{l}\mathrm{RMSEC}^{\mathrm{a}} \\
\mathrm{g} \mathrm{C} \mathrm{kg}^{-1}\end{array}$ & RMSEC/SD & $\mathrm{N}$ & $\begin{array}{l}\mathrm{RMSEP}^{\mathrm{b}} \\
\mathrm{g} \mathrm{C} \mathrm{kg}^{-1}\end{array}$ & $\mathrm{RPD}^{\mathrm{c}}$ & $\mathrm{R}^{2}$ \\
\hline ASD & 108 & 2.8 & 0.45 & 37 & 3.3 & 1.79 & 0.82 \\
\hline $\mathrm{ASD}^{\mathrm{d}}$ & 77 & 1.7 & 0.25 & 24 & 2.4 & 2.33 & 0.90 \\
\hline CASI (Ortho) & 94 & 3.0 & 0.93 & 32 & 4.4 & 1.08 & 0.44 \\
\hline CASI (Attert) & 75 & 3.4 & 0.51 & 24 & 3.8 & 1.97 & 0.87 \\
\hline Casi+SASI & 73 & 2.9 & 0.60 & 26 & 1.9 & 2.50 & 0.92 \\
\hline
\end{tabular}

${ }^{a}$ Root mean square error of calibration

${ }^{\mathrm{b}}$ Root mean square error of prediction

${ }^{\mathrm{c}}$ Ratio of performance to deviation (RMSEP/SD)

${ }^{\mathrm{d}}$ Only including the dataset of dry soil surfaces

of its intensity and duration. Depending on the type of threat, different soil functions may be affected (Table 7.4). In some cases more than one threat occur on a certain piece of land.

The combination of threats sometimes worsens their effect on soil functions. As illustrated in Fig. 7.1, which summarises the DIGISOIL concept, the core objectives of the program are focused on determining the most relevant soil properties, which in a second phase (and through the use of pedo- and hydro-models, as well as auxiliary data) will allow us to map soil threats and functions (Tables 7.3 and 7.4). In the last decades, geophysical prospecting applied to subsurface characterisation has been of an increasing interest, particularly in soil science. Major advances in this technological domain can be attributed to the development of integrated measuring systems, increasing computing power, equipment portability, and hardware/software diffusion. In this context, two kinds of technological platforms can be involved: ground-based and proximal technologies, working from the surface and from the air. Ground-based geophysical instruments are now equipped with digital signal processing and recording capabilities previously restricted to large corporate computing centres. This improved computational capacity has provided investigators with near real-time results that, in turn, drive improvements in instrument sensors and processing algorithms. In a similar way, recent airborne geophysics has sparked strong interest due to the possibilities of civil airplanes equipped with optical, thermal, or hyperspectral sensors. The most common methods that take advantage of these enhancements, and their related parameters, are listed in Table 7.5.

Measuring the electrical resistivity of soil was proposed in the DIGISOIL project because it is closely related to several soil parameters and can be performed over areas of several hectares with high resolution (Panissod et al., 1997; Chapter 26, this volume). Up to now, the interpreting electrical measurements have remained difficult because the different influences soil parameters have on electrical resistivity are still hard to discriminate. There are numerous relationships between electrical resistivity and any one soil physical or chemical parameter. For example, there are 
linear (or more complex) correlations between electrical resistivity and soil temperature (Keller and Frischknecht, 1966), soil water content and salinity (Sen et al., 1988), soil cationic exchange capacity (Shainberg et al., 1980), soil texture (i.e. clay content), and soil porosity (Friedman, 2005). Other studies have demonstrated the influence of soil structure on electrical resistivity, such as the impact of bulk density or the effect of cracks (Samouëlian et al., 2003).

Spatial electrical investigations therefore enable us to describe soil structural heterogeneity, with the aim of delineating specific zones for use in precision agriculture or to map soil texture (Tabbagh et al., 2000) or salinity (Corwin et al., 2006). Nevertheless, despite these known relationships, it remains difficult to describe the effect of ancillary parameters on electrical resistivity, especially the effect of the soil structure (which changes quickly under the influence of water content and temperature). To address these issues, specific experiments will be conducted in the DIGISOIL project, such as taking measurements that should help describe the evolution of at least one or two parameters (assuming the others remain constant). As an example, Fig. 7.2 shows three electrical resistivity maps recorded at three dates when only the soil water content was supposed to vary (Besson et al., 2008).

Other studies will evaluate the possibility of using field spectroscopy (Chapter 11) to estimate carbon content (Stevens et al., 2006). Visible and nearinfrared (VNIR) spectral analysis and diffuse reflectance analysis are techniques that can rapidly quantify various soil characteristics simultaneously (Ben-Dor and Banin, 1995; Viscarra Rossel et al., 2006). There are three types of VNIR techniques (Chapter 13), which operate at different spatial scales and in different environments: (1) laboratory spectroscopy (LS); (2) portable field spectroscopy (PS); and (3) imaging spectroscopy (IS). LS and PS rely on ground-based sensors (such as the Fieldspec Pro FR from Analytical Spectral Devices covering 350-2,500 nm). IS uses air- or space-borne sensors such as the Compact Airborne Spectrographic Imager or CASI (covering 405-950 $\mathrm{nm}$ ) and the Shortwave Infrared Airborne Spectrographic Imager (SASI), covering 900-2,500 nm). Two different test sites in southern Belgium were monitored within the framework of the Belgian airborne imaging spectroscopy campaigns under the PRODEX program. The aim was to explore the capabilities of VNIR spectroscopy in the context of soil organic carbon (SOC) inventories and monitoring. The sites, Ortho in the Ardennes $\left(50^{\circ} 8^{\prime}\right.$ $\left.\mathrm{N}, 5^{\circ} 36^{\prime} \mathrm{E}\right)$ and Attert $\left(49^{\circ} 45^{\prime} \mathrm{N}, 5^{\circ} 44^{\prime} \mathrm{E}\right)$, were overflown with a CASI sensor in October 2003 when cereal fields had been ploughed, harrowed, and reseeded.
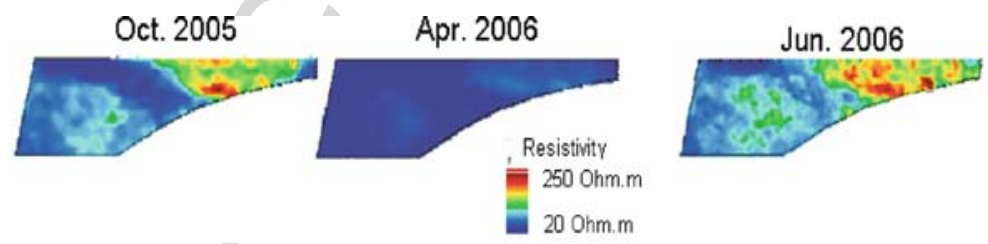

Fig. 7.2 Resistivity maps for three dates showing the impact of water saturation in soils on electrical resistivity (Besson et al., 2008) 
Exactly 120 soil spectra from 13 bare fields were taken at Ortho and 40 from 10 bare fields at Attert using the Fieldspec Pro (ASD). At the same sites, topsoil $(0-5 \mathrm{~cm})$ samples were taken and analysed for moisture content and organic carbon content (the latter by wet oxidation). Furthermore, three bulk density samples were taken in each field in order to calculate the SOC stock in the ploughed layer (mean thickness $22 \mathrm{~cm}$ ). Another dataset from a previous IS campaign near Attert, using both CASI and SASI sensors, was also analysed. We used both stepwise and partial least square (PLS) regression analysis to relate spectral measurements to SOC content. Root mean square error of prediction (RMSEP) for the ASD ranged from 2.4 to $3.3 \mathrm{~g} \mathrm{C} \mathrm{kg}^{-1}$ depending on soil moisture content of the surface layer (Table 7.4). Imaging spectroscopy performed poorly, mainly due to the narrow spectral range of the CASI. Tests using both the CASI and the SASI performed better. The variation in soil texture and soil moisture content degrades the spectral response to SOC contents. Currently, RMSEP allows us to detect an SOC stock change of 1.9-4.4 g $\mathrm{C} \mathrm{kg}^{-1}$ or $4.2-9.9 \mathrm{Mg} \mathrm{C} \mathrm{ha}^{-1}$ in the upper $22 \mathrm{~cm}$ of the soil and is therefore still somewhat high, at least in comparison with changes in SOC stocks resulting from management or land conversion reported in the literature $\left(0.3-1.9 \mathrm{MgC} \mathrm{ha}^{-1}\right.$ $\mathrm{yr}^{-1}$; Freibauer et al., 2004). A detailed SOC map produced by IS reflected the patterns in SOC content due to the site's recent conversion from grassland to cropland (Fig. 7.3).

Accuracy of the spectral techniques is lower than that of most routine laboratory SOC analyses. However, the large number of samples that can be analysed by hyperspectral techniques outweighs the slight loss of precision compared to

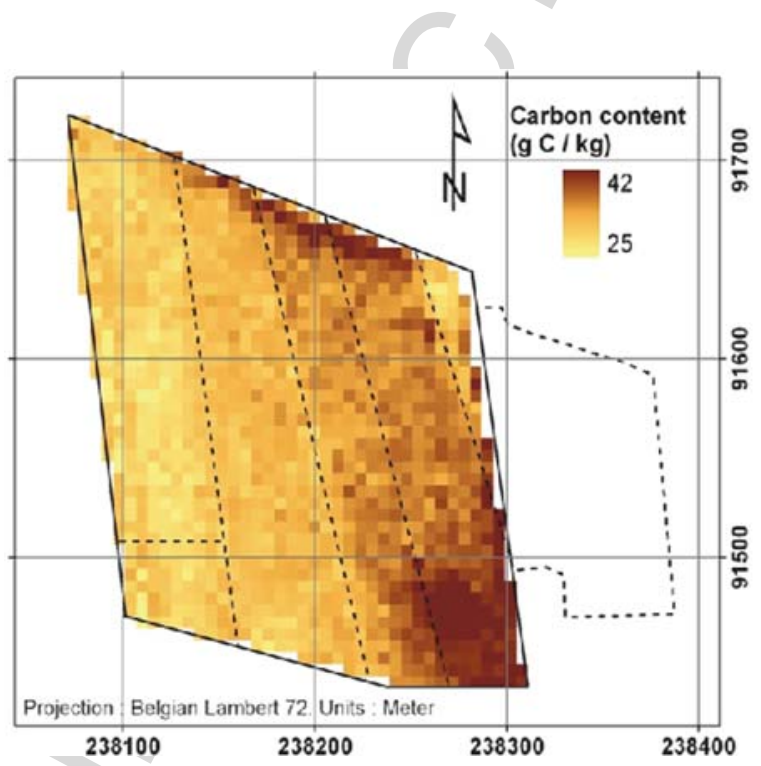

Fig. 7.3 Map of soil organic carbon content in a freshly ploughed field after land consolidation. The borders of the original fields that were joined are indicated with dashed lines (Stevens et al., 2006) 
traditional chemical analyses. The greatest potential lies in airborne applications because imaging spectroscopy can cover a wide region almost instantaneously and produce thousands of samples. Relatively poor detection levels are attributed to sensor characteristics (artefacts, noise, and limited spectral range) and factors affecting the soil spectral response (limited variability in SOC content, disturbing factors). The problem of disturbing factors will be addressed in the DIGISOIL project, through an experimental study of the effect of soil moisture, soil texture, and soil roughness on reflectance. Experiments on soil texture recovery, particularly wellsuited for distinguishing between calcite and clayed minerals and using ULM's onboard sensors, have already begun (Fig. 7.4). Furthermore, specifications for airborne sensors as well as the optimal strategy for calibration and validation will be documented.

Ground-penetrating radar (GPR) is an increasingly used non-invasive and proximal electromagnetic (EM) sensing technology that can image the subsurface

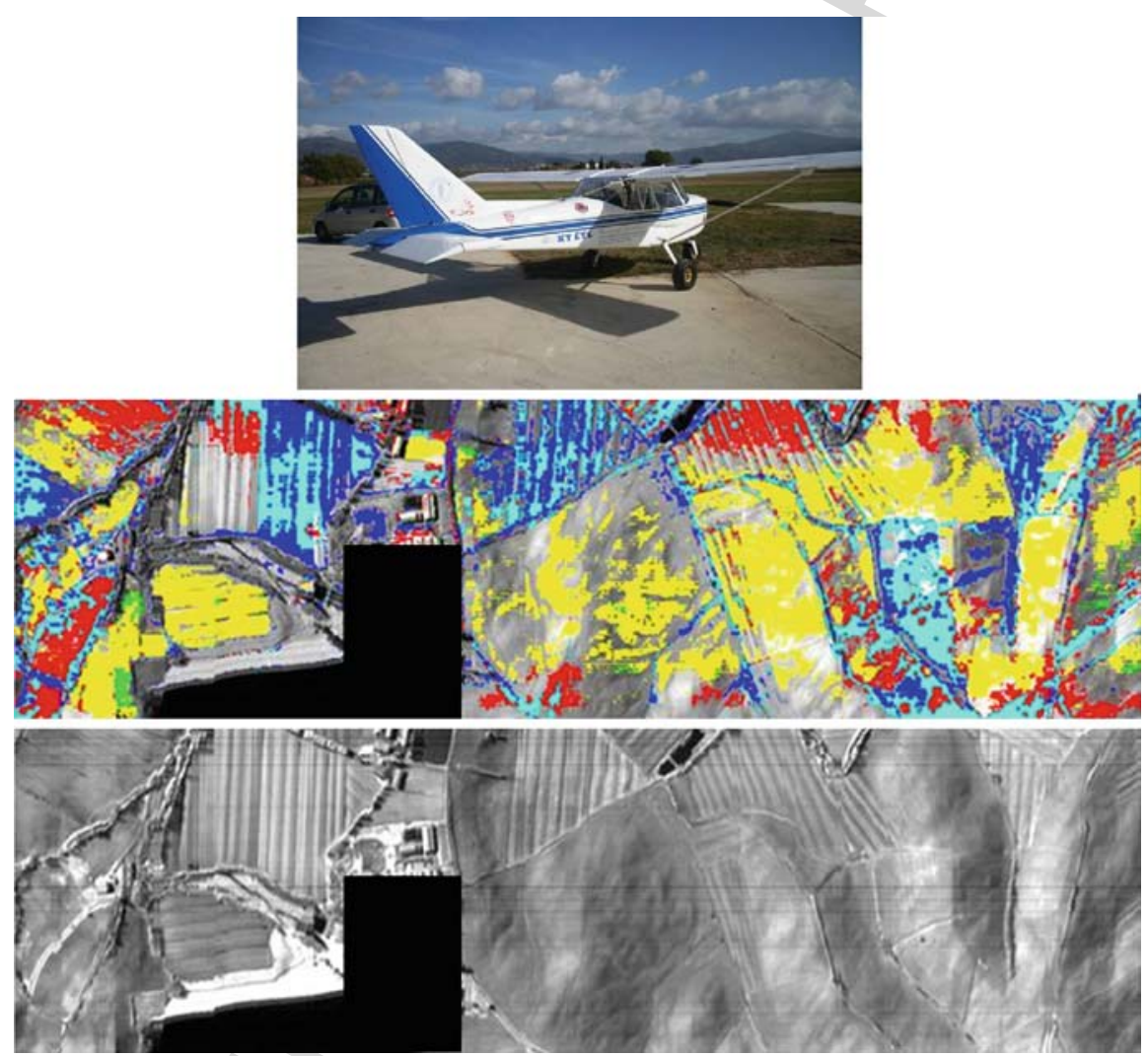

Fig. 7.4 ULM facility and resulting images: one based on Spectral Angle Mapper (SAM) classification; the second based on SWIR data where absorption bands of mineral clays $(2.0-2.4 \mu \mathrm{m})$ are present (Univ. Firenze). Red: calcite, green: chlorite, yellow: illite, blue: illite-smectite, cyan: smectite 
and identify its physical properties (Chapter 25). It is based on sending electromagnetic radiation (ultra-wideband VHF-UHF) into the soil and recording the reflected signals. In areas of agricultural and environmental engineering, GPR has been used to identify soil vertical structures, locate water tables, follow wetting front movement, identify soil hydraulic parameters, measure soil water content, assess soil salinity, monitor contaminants, and delineate soil compaction. Nevertheless, existing GPR techniques still suffer from major limitations due to simplifying assumptions on which they rely, particularly about EM wave propagation. In general, the radar system and antennas are not accounted for, ray approximation is applied to describe GPR wave propagation, and only the propagation time to reflectors is considered in signal processing algorithms. Reflection amplitude can also be used, but this is limited to the surface reflection for airborne GPR, and requires calibrations that are not practical for automated and real-time mapping. As a result, only a part of the information contained in the GPR data is usually used, and significant errors in the estimates are often introduced. To circumvent these shortcomings, Lambot et al. (2004) have recently developed a new approach: stepped-frequency continuous-wave monostatic off-ground GPR. The off-ground mode is particularly appropriate for real-time mapping of shallow subsurface properties. The radar system is based on ultra-wideband vector network analyser (VNA) technology. In contrast to classical GPR systems, the physical quantity measured by a VNA is exactly known and defined as an international standard. This permits the use of advanced full-waveform forward and inverse modelling techniques to estimate soil EM properties from the GPR signal, which intrinsically maximises information retrieval from the recorded data. In that respect, Lambot et al. (2004) developed a remarkably accurate EM model for their specific radar configuration, which included internal antenna and antenna-soil interaction propagation effects; they were able to exactly solve the three-dimensional Maxwell equations for wave propagation in multilayered media. Through GPR signal inversion, the approach has been successfully validated in a series of controlled hydrogeophysical experiments for electromagnetic soil characterisation (which included dielectric permittivity, electric conductivity, and frequency dependence of these quantities). GPR data inversion has been also integrated with hydrodynamic modelling to retrieve soil hydraulic properties from time-lapse radar data and to monitor the dynamics of continuous water content profiles (Lambot et al., 2006). In addition, the technique improves shallow subsurface imaging, which represents an important asset for determining high-resolution soil stratigraphy. Figure 7.5 shows an example of a field application where the developed method is used for real-time mapping of the soil surface dielectric permittivity and correlated water content, bridging the spatial scale gap between traditional soil sampling and remote sensing in hydrology.

To complement the above-cited techniques, DIGISOIL aims also to explore innovative geophysical methods for characterising specific soil properties. In particular, seismic methods will be tested in order to quantify the soil's mechanical modulus, a parameter closely related to soil compaction (Grandjean, 2006). Already validated in geotechnics for investigating zones tens of metres in extent, the challenge will be in adapting the methodology to small seismic devices, i.e. zones of several metres. 
HYDRASENS Field campaign 07/04/2008 Electrical conductivity estimated by EM38
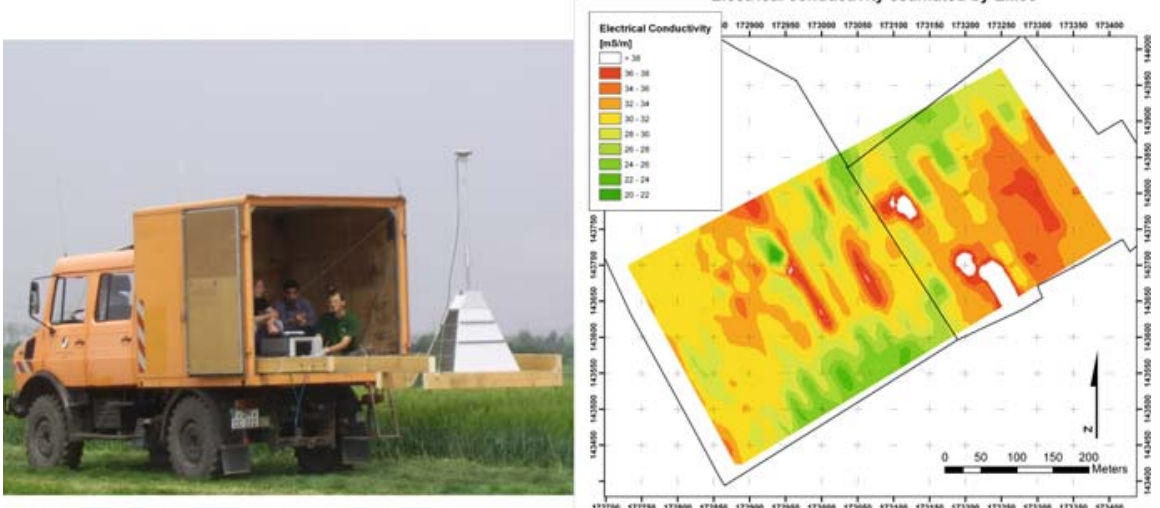

Fig.7.5 Real-time mapping of soil surface water content with advanced GPR (Lambot et al., 2006)

\subsection{Conclusions}

In order to assess and prevent soil degradation, and to benefit from the different ecological, economic, and historical functions of the soil in a sustainable way, there is an obvious need for high-resolution, accurate maps of soil properties. The core objective of the project is to explore and exploit new capabilities of advanced geophysical technologies for answering this societal demand. Some geophysical techniques that will be carried out in the project are based on positive experiences in the domain and promise to fulfil the objectives of the project. Electrical and GPR measurements, hyperspectral imagery, and more innovative methods like seismic methods will be tested and technically adapted to soil properties mapping. An important output of the project will concern the use of related soil properties in an application dedicated to digital soil mapping (Chapter 5).

Acknowledgement The DIGISOIL project is financed by the European Commission under the 7th Framework Program for Research and Technological Development, Area 'Environment', Activity 6.3 'Environmental Technologies'.

\section{References}

Ben-Dor E, Banin A (1995) Near infrared analysis (NIRA) as a rapid method to simultaneously evaluate several soil properties. Soil Sci Soc Am J 59:364-372

Besson A, Cousin I, Bourennane H, Pasquier C, Nicoullaud B, Richard G, King D (2008) Discretization of spatial and temporal soil water variability into homogeneous zones based on electrical resistivity measurements at the field scale. EUROSOIL congress 2008, Soil, Society, Environment, 25-29/08/2008, Vienna

Corwin DL, Lesch SM, Oster JD, Kaffka SR (2006) Monitoring management-induced spatiotemporal changes in soil quality through soil sampling directed by apparent electrical conductivity. Geoderma 131:369-387 


\section{DIGISOIL: An Integrated System of Data Collection Technologies}

Freibauer A, Rounsevell MDA, Smith P, Verhagen J (2004) Carbon sequestration in the agricultural soils of Europe. Geoderma 122:1-23

Friedman SP (2005) Soil properties influencing apparent electrical conductivity: a review. Comput Electron Agric 46:45-70

Grandjean G (2006) A seismic multi-approach method for characterizing contaminated sites. J Appl Geophys 58:87-98

Keller GV, Frischknecht FC (1966) Electrical methods in geophysical prospecting. Pergamon, Oxford

Lambot S, Slob EC, van den Bosch I, Stockbroeckx B, Vanclooster M (2004) Modeling of groundpenetrating radar for accurate characterization of subsurface electric properties. IEEE Trans Geosci Remote Sens 42:2555-2568

Lambot S, Slob EC, Vanclooster M, Vereecken H (2006) Closed loop GPR data inversion for soil hydraulic and electric property determination. Geophys Res Lett 33:L21405, doi:10.1029/2006GL027906

Panissod C, Dabas M, Jolivet A, Tabbagh A (1997) A novel mobile multipole system (MUCEP) for shallow (0-3 m) geoelectrical investigation: the 'Vol-de-canards' array. Geophys Prospect 45:983-1002

Samouëlian A, Cousin I, Richard G, Tabbagh A, Bruand A (2003) Electrical resistivity imaging for detecting soil cracking at the centimetric scale. Soil Sci Soc Am J 67:1319-1326

Sen PN, Goode PA, Sibbit, A (1988) Electrical conduction in clay bearing sandstones at low and high salinities. J Appl Phys 63:4832-4840

Shainberg I, Rhoades JD, Prather RJ (1980) Effect of ESP, cation exchange capacity and soil solution concentration on soil electrical conductivity. Soil Sci Soc Am J 44:469-473

Stevens A, van Wesemael B, Vandenschrieck G, Tychon B, Touré S (2006) Detection of carbon stock change in agricultural soils using spectroscopic techniques. Soil Sci Soc Am J 70:844-850

Tabbagh A, Dabas M, Hesse A, Panissod C (2000) Soil resistivity: a non-invasive tool to map soil structure horizonation. Geoderma 97:393-404

Viscarra Rossel RA, Walvoort D, McBratney AB, Janik L, Skjemstad J (2006) Visible, near infrared, mid infrared or combined diffuse reflectance spectroscopy for simultaneous assessment of various soil properties. Geoderma 131:59-75

Viscarra Rossel RA, Taylor HJ, McBratney AB (2007) Multivariate calibration of hyperspectral gamma-ray energy spectra for proximal soil sensing. Eur J Soil Sci 58:343-353

Wilford J, Minty B (2006) The use of airborne gamma-ray imagery for mapping soils and understanding landscape processes. In: Lagacherie P, McBratney AB, Voltz M (eds) Digital soil mapping: an introductory perspective. Elsevier Science, Amsterdam, 600 pp 